\title{
LunarEX—a proposal to cosmic vision
}

\author{
A. Smith • I. A. Crawford • R. A. Gowen - A. J. Ball • S. J. Barber • \\ P. Church - A. J. Coates • Y. Gao - A. D. Griffiths • A. Hagermann • \\ K. H. Joy • A. Phipps • W. T. Pike • R. Scott • S. Sheridan • M. Sweeting • \\ D. Talboys · V. Tong $\cdot$ N. Wells $\cdot$ J. Biele $\cdot$ J. Chela-Flores $\cdot$ B. Dabrowski • \\ J. Flannagan • M. Grande · J. Grygorczuk • G. Kargl • O. B. Khavroshkin • \\ G. Klingelhoefer • M. Knapmeyer • W. Marczewski - S. McKenna-Lawlor • \\ L. Richter • D. A. Rothery • K. Seweryn - S. Ulamec • R. Wawrzaszek • \\ M. Wieczorek • I. P. Wright • M. Sims
}

Received: 29 January 2008 / Accepted: 19 June 2008 / Published online: 21 August 2008

(C) The Author(s) 2008. This article is published with open access at Springerlink.com

\author{
A. Smith $(\varangle) \cdot$ R. A. Gowen · A. J. Coates · A. D. Griffiths \\ Mullard Space Science Laboratory, University College London, \\ Holmbury St Mary, Dorking Surrey, RH5 6NT, UK \\ e-mail: as@mssl.ucl.ac.uk \\ I. A. Crawford · K. H. Joy · V. Tong \\ Birkbeck College, University of London, London, UK
}

\author{
A. J. Ball · S. J. Barber · A. Hagermann - S. Sheridan · D. A. Rothery · I. P. Wright \\ CEPSAR, Open University, Milton Keynes, UK \\ P. Church · R. Scott \\ QinetiQ Ltd., Fort Halsted, Sevenoaks, UK \\ Y. Gao \\ Surrey Space Centre, University of Surrey, Guildford, UK
}

A. Phipps · M. Sweeting

SSTL, Tycho House, 20 Stephenson Road, Guildford, UK

W. T. Pike

Imperial College London, London, UK

D. Talboys $\cdot$ M. Sims

University of Leicester, Leicester, UK

N. Wells

QinetiQ Ltd., Cody Technology Park, Farnborough, UK

J. Biele · S. Ulamec

DLR, Cologne, Germany 
Abstract While the surface missions to the Moon of the 1970s achieved a great deal, scientifically much was also left unresolved. The recent plethora of lunar missions (flown or proposed) reflects a resurgence in interest in the Moon, not only in its own right, but also as a record of the early solar system including the formation of the Earth. Results from recent orbiter missions have shown evidence of ice or at least hydrogen within shadowed craters at the lunar poles.

Keywords Lunar • Penetrator • Lunar seismology • Lunar geochemistry • Lunar geophysics • Lunar exploration

This paper describes a Cosmic Vision proposal for a highly cost effective Medium-class lunar mission that would place 4 or more scientifically instrumented penetrators into the lunar surface.

LunarEX would address key issues related to the origin and evolution of planetary bodies as well as the astrobiologically important possibilities

\section{J. Chela-Flores}

The Abdus Salam International Centre for Theoretical Physics, Trieste, Italy

B. Dabrowski · J. Grygorczuk · W. Marczewski · K. Seweryn · R. Wawrzaszek Space Research Centre, Polish Academy of Sciences, Warsaw, Poland

\section{J. Flannagan}

ORC, University of Southampton, Southampton, UK

M. Grande

Institute of Mathematical and Physical Sciences, University of Wales Aberystwyth,

Aberystwyth, UK

G. Kargl

Space Research Institute, Austrian Academy of Sciences, Graz, Austria

O. B. Khavroshkin

United Institute of Physics of the Earth, Russian Academy of Sciences, Moscow, Russia

G. Klingelhoefer

Institute for Inorganic and Analytical Chemistry,

Johannes Gutenberg-University, Mainz, Germany

M. Knapmeyer

Institute of Planetary Research, DLR, Berlin, Germany

S. McKenna-Lawlor

Department of Experimental Physics,

National University of Ireland, Maynooth, Ireland

L. Richter

DLR, Bremen, Germany

M. Wieczorek

Institut de Physique du Globe de Paris, Paris, France 
associated with polar ice. LunarEX would provide important information about:

- The size and physical state of the lunar core

- The deep structure of the lunar mantle

- The thickness of the farside lunar crust

- The nature of natural moonquakes, in particular the origin of shallow moonquakes

- The composition and thermal evolution of the Moon's interior

- The existence, nature and origin of polar ice-exciting scientifically and key to future manned exploration of the Moon and beyond

The penetrators would be globally dispersed (unlike the Apollo missions) with landing sites on the nearside Procellarum KREEP Terrain, poles and farside, and would operate $2-5 \mathrm{~m}$ beneath the lunar surface for 1 year powered by non-recharged Li batteries.

Each penetrator includes a suite of scientific instruments including microseismometers, a geochemistry package, a water/volatiles detector (for the polar penetrator(s)), a heat flow experiment, and an impact accelerometer.

For an instrument to survive an impact at $300 \mathrm{~ms}^{-1}$ is entirely feasible and a vast amount of resource has been devoted to such conditions within a defence context. 'Penetrators' are common-place within that sector and instrumentation is available off-the-shelf which will survive impacts of $>50,000 \mathrm{~g}$ (LunarEX expects up to $10,000 \mathrm{~g}$ ). This expertise is by no means purely empirical in nature; a very sophisticated predictive modeling capability also exists. The LunarEX project planned to tap this capability for a scientific end. Moreover, Mars 96, DS-2 and Lunar-A penetrator development programmes have overcome many key problems and demonstrated survivability in ground tests.

The penetrator delivery to the lunar surface would take place in two stages:

- The Penetrators will be transferred to lunar orbit as the payload of what will become a polar orbit communications relay satellite

- Release, de-orbit and descent. Each penetrator will have an attached de-orbit motor and attitude control systems (both of which are ejected before impact)

The mission is compatible with a single Soyuz-Fregat launch for a nominal 4 penetrator payload with a $30 \%$ mass contingency.

LunarEX would fill an important gap within the proposed international lunar mission portfolio and facilitate the future scientific and ultimately manned exploration of the Moon. While ultimately not selected under Cosmic Vision the associated MoonLITE project has gone on as the basis for a joint UK-NASA phase A mission study. This study benefits significantly from the work reported here. 


\section{Introduction}

\subsection{The moon}

The principal scientific importance of the Moon is as a recorder of geological processes active in the early history of terrestrial planets (e.g. planetary differentiation, magma ocean formation and evolution), and of the near-Earth cosmic environment (e.g. bombardment history, solar wind flux and composition) throughout Solar System history [e.g. [3, 26, 34]]. Some of these objectives are astrobiological in nature, in that they will enhance our understanding of the cosmic conditions under which life first arose on Earth [4]. However, although the Clementine and Lunar Prospector missions have in recent years greatly added to our knowledge of the geochemical and mineralogical makeup of the lunar surface (see, e.g. [14]), our knowledge of the interior still largely relies on geophysical measurements made during the Apollo programme. As can be seen from Fig. 1, these landing sites are all located at low to midlatitudes close to the centre of the lunar nearside, and were thus unable to provide anything approaching global coverage. In order to build on the Apollo data, and thus advance our knowledge of lunar science, the LunarEX mission would fly $4+$ penetrators to the Moon for the purpose of conducting a range of in situ geophysical and geochemical measurements at widely separated localities.

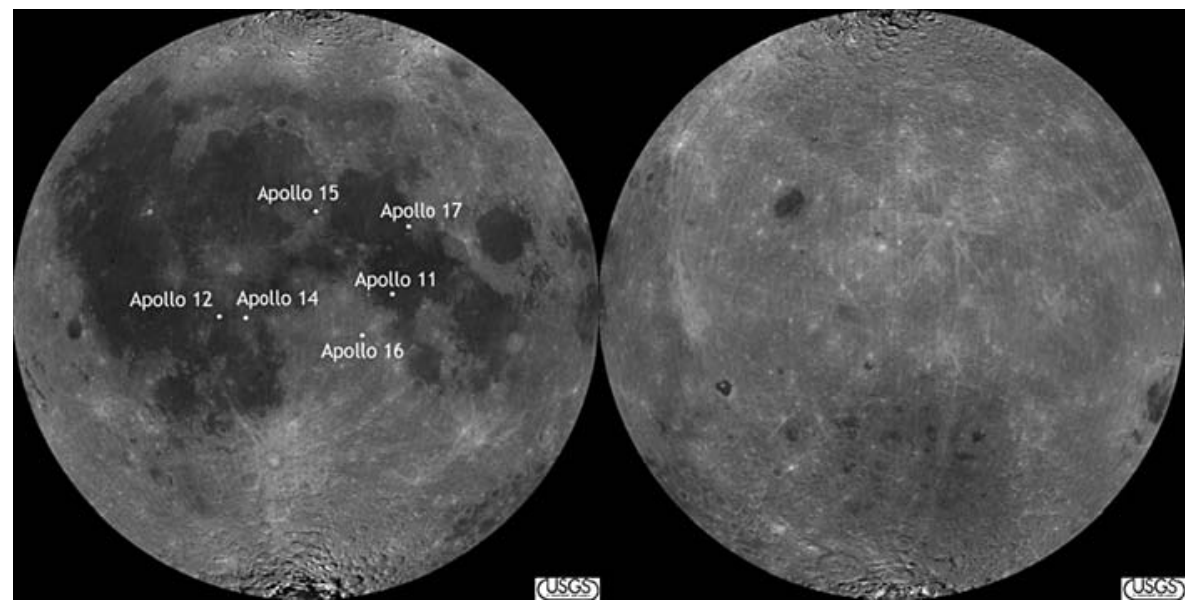

Fig. 1 Locations of the Apollo landing sites on the nearside of the Moon (left); the farside is at right. The Apollo seismic network occupied an approximate equilateral triangle, roughly 1,200 km on a side, defined by the Apollo 15 site at the northern apex, Apollos 12 and 14 (close together at the SW apex), and Apollo 16 at the SE apex. The two Apollo heat-flow measurements were made at the Apollo 15 and 17 sites. No long-term geophysical measurements were made at the Apollo 11 site. Note the geographically restricted nature of these measurements (background (image courtesy of the USGS) 


\subsection{Penetrators}

Penetrators allow key scientific investigations of airless solar system bodies via affordable pre-cursor missions. In fact, it is difficult to envisage any other method which allows globally spaced surface exploration of airless planetary bodies that is not prohibitively expensive.

(Kinetic) Penetrators (e.g. see Fig. 2) are small probes which impact planetary bodies at high speed and bury themselves into the planetary surface. For the Moon we propose deployment of $\sim 13 \mathrm{Kg}$ penetrators that are designed to survive impact at high speed $(\sim 300 \mathrm{~m} / \mathrm{s})$ and penetrate $\sim 2-5 \mathrm{~m}$. The impact process generates decelerations of up to $10,000 \mathrm{~g}$, which together with the low mass, restricts the type and capability of payload that can be accommodated. However, a surprisingly large range of instruments have already been constructed and qualified for penetrator use, and an ever widening range of scientific instruments have a robust nature and lend themselves to the necessary ruggedisation. Of course, multiple penetrators allow a natural level of redundancy.

Survival at these impact speeds has been demonstrated by ground tests of NASA DS2 and Japanese Lunar-A probes, and extensive defence experience of impacts into materials mostly consisting of sand, concrete, steel and ice.

\subsection{Current and future space missions}

Though there are several orbiter space missions either recently launched or with a launch expected in 2008 (SELENE, Chang'e, Chandrayaan-1, Lunar Reconnaissance Orbiter-LRO), none of these will be able to address the main science issues we propose that require a seismic network, or provide in situ ground truth investigation of water/volatile deposits in the sub-surface lunar polar regolith. The Lunar Prospector impact produced no useful data about the Moon's composition. The NASA LRO mission includes an impactor (LCROSS) with a flyby investigation of the resulting material thrown high up above the lunar surface. This could be capable of detecting water. The deployment of multiple penetrators with LunarEX would provide ground truth corroboration, and multi-site quantitative characterisation of any LRO and other mission results.

In addition to the cancelled Japanese Lunar-A project [22] (which performed full-scale impact demonstration of a Lunar penetrator) at least two

Fig. 2 Penetrator schematic

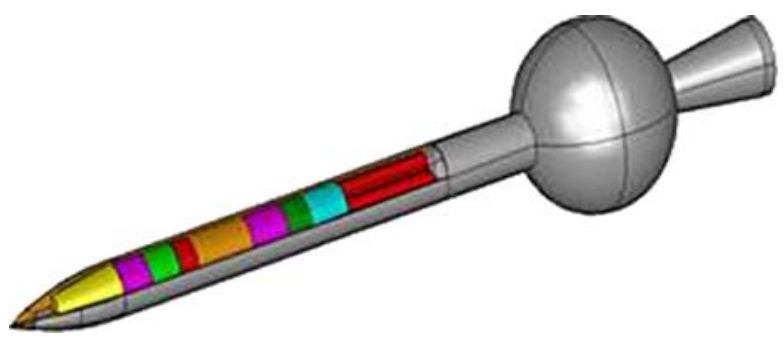


other Lunar Penetrator missions have been proposed. These are the Russian Lunar Glob mission (which may include Japanese penetrators) and the Polar Night proposal to NASA. Polar Night [19] envisages three penetrators targeted at shaded craters and is primarily concerned with the identification and characterisation of volatiles.

LunarEX is based on the MoonLITE mission concept [6]. A UK-NASA Joint working group recommended that MoonLITE undergo a phase-A study.

In summary, a mission such as LunarEX has the potential to provide exciting lunar science; provide information about the existence, concentration and form of any water ice deposits important for future lunar manned exploration; provide a confidence building technical demonstration of penetrator technology applicable to cost effective pre-cursor in situ exploration of other solar system bodies; and enable development of a technical capability.

\section{Scientific objectives}

The top-level science objectives for LunarEX fall into four categories: seismology, heat-flow, geochemical analysis, and polar volatile detection.

\subsection{Lunar seismology}

Seismology is the most powerful geophysical tool available to us for determining the interior structure of a planetary body. However, to-date the only object, other than the Earth, where it has been applied with some success is the Moon, where the Apollo missions deployed a network of four highly sensitive seismometers close to the centre of the nearside. The Apollo seismometers remained active for up to 8 years during which they provided important information on the Moon's natural seismic activity, and the structure of the lunar crust and upper mantle (see [8] and [15] for reviews). However, the deep interior of the Moon was only very loosely constrained by the Apollo seismology — the physical state and composition, of any lunar core remains uncertain.

The main problem was that the Apollo seismometers were deployed in a geographically limited triangular network (between Apollo 12/14, 15 and 16; Fig. 1) on the nearside. As a consequence, the information obtained on crustal thickness and upper mantle structure strictly only refers to the central nearside and may not be globally representative. Moreover, seismic waves capable of probing the deep interior had to originate close to the centre of the farside, and were therefore limited to rare, relatively strong, events. Indeed, the tentative seismic evidence for a lunar core arises from the analysis of just one farside meteorite impact that was sufficiently strong to be detected by more than one nearside Apollo seismic station in 8 years of operation. This is clearly an unsatisfactory state of affairs, and there is a pressing need for a much more widely-spaced network of lunar seismic stations, including stations at high latitudes and on the farside. Penetrators delivered from orbit are ideally suited 
as a means of emplacing a global seismometer network, which would address the following scientific issues:

\subsubsection{Size and physical state of lunar core}

As the Apollo seismic data were unable to constrain the size or physical state of the lunar core, such knowledge as we have has been obtained from studies of the Moon's moment of inertia, physical librations (as determined by laser reflector measurements), and electromagnetic induction studies (see [37] for a review). These studies favour a small $(\mathrm{R}<400 \mathrm{~km})$ partially liquid core, with suggested compositions ranging from iron-nickel, Fe-FeS alloy, or molten silicates. Whether this liquid 'core' possesses a solid inner core is currently unknown. Information on the size, composition and physical state of a lunar core would have profound impacts on our understanding of the Moon's origin, mantle evolution, and magnetic history. The latter point, when combined with studies of remnant magnetisation of surface rocks, will have important implications for our understanding of the origin and evolution of planetary magnetic fields. For these reasons, constraining the nature of any lunar core is the top scientific priority of the penetrator-deployed seismic network.

\subsubsection{Deep structure of the lunar mantle}

One of the main contributions that lunar science can make to planetary science more generally is an enhanced understanding of the internal differentiation processes that occur immediately after the accretion of a terrestrial planet. Magma oceans are likely to have been a common phase in the early evolution of all rocky planets, and, in contrast to the more evolved mantles of the larger terrestrial planets, the structure of the lunar mantle may preserve a record of this early state. Seismology may help elucidate these processes in several ways.

Most fundamentally, seismology may be able to determine the initial depth of the magma ocean, and thus the fraction of the Moon's volume that was initially molten. The Apollo data appear to indicate a seismic discontinuity at a depth of about $550 \mathrm{~km}$, which is sometimes interpreted as the base of the magma ocean (see review by [37]). However, because of the placement of the Apollo seismometers, it is not currently known whether this discontinuity is global in extent or exists only under the nearside. A competing explanation is that it represents the depth to which later partial melting has occurred which led to the formation of the nearside mare basalts. As noted by Wieczorek et al. [37], distinguishing between these two possibilities is of key importance in understanding lunar mantle evolution.

In addition, measurements of seismic wave speed as a function of depth help constrain the mineralogy of the mantle (e.g. [16]). This in turn may be used to constrain both the bulk composition of the Moon (and thus its origin), and the crystallisation history of the lunar mantle and its implications for magma ocean evolution. Again, new, and more widely spaced, seismic data are now 
required if new advances are to be made over what has been learned from the Apollo data.

\subsubsection{Thickness of the farside lunar crust}

Reinterpretations of the Apollo seismic data have now constrained the thickness of the nearside anorthositic crust to about 30-40 km [12, 16, 37]. However, the thickness of the farside crust has not been constrained seismically at all. Estimates based on gravity data are typically in the range $70-90 \mathrm{~km}$ [37], but these are non-unique, and in particular depend on whether the lunar highland crust should be considered as a single anorthositic layer, or as two layers with the lower layer having a more mafic (Fe-rich) composition. Farside measurements are required in order to determine the average lunar crustal thickness which, because of its very aluminium-rich nature, has significant implications for understanding the bulk composition (and thus origin) of the Moon.

In addition, there is considerable interest in the thickness of the crust (if any) remaining under the giant South Pole-Aitken (SPA) impact basin on the farside - the largest impact structure currently known in the Solar System. Together with the nearside Procellarum KREEP Terrain (well studied by Apollo) and the farside highlands, the floor of the SPA forms one of the three main lunar terrains identified by Jolliff et al. [11]. Part of the interest in the SPA lies in the possibility that it may have exposed lower crustal or upper mantle materials. Seismometers located within the SPA would, for the first time, be able to make a definitive measurement of the crustal thickness remaining under this important structure.

\subsubsection{Studies of natural moonquakes}

The Apollo seismometers detected four types of natural Moonquake: (1) deep (700-1,200 km), relatively weak, moonquakes which occur in 'nests' and which appear to have a tidal origin; (2) shallow (5-200 km), relatively strong, moonquakes of unknown origin; (3) thermal moonquakes due to thermal stresses in the near surface; and (4) meteorite impacts (summarised by [35]). Of these (1), (2) and (4) may be used as sources of seismic energy to probe the lunar interior, and a better understanding of the causes and clustering of (1) will provide additional knowledge of the physical properties of the deep lunar interior.

However, it is the shallow Moonquakes (2) that are probably the most interesting scientifically. These were the strongest (up to magnitude 5) and rarest (only 28 recorded in 8 years), and currently their cause is unknown. Insofar as these result from unknown tectonic processes, our knowledge of present-day lunar geological activity will remain incomplete until their cause and locations can be identified (e.g. [23]). Owing to the spatially restricted locations of the Apollo seismic stations, the Apollo data lacks the resolution 
to pinpoint the precise epicentres or depths of these events, for which a global distribution of seismometers will be required.

Understanding these events is also important in the context of future lunar exploration. For example, a magnitude 4-5 Moonquake is sufficiently strong that it would be prudent not to construct a lunar base at localities where they are likely to occur [25]. Some scenarios for future lunar exploration also envisage placing optical astronomical instruments on the lunar surface, and knowledge of lunar seismicity could be useful in deciding where to site such instruments. Thus, in addition to providing fundamental information about lunar geophysics, a better understanding of the origins and locations of shallow moonquakes would make a significant contribution to future lunar exploration.

\subsection{Lunar heat-flow}

Measurements of surface heat-flow provide valuable constraints on the composition and thermal evolution of planetary interiors. To date, the only planetary body other than the Earth for which surface heat-flow has been measured in situ is the Moon, during the Apollo 15 and 17 missions [13]. However, both these measurements were relatively close together on the nearside and may thus not be representative of the lunar heat-flow as a whole. Moreover, both these Apollo measurements have been subject to numerous re-interpretations, owing to uncertainties in determining the thermal conductivity of the regolith, the extent to which the temperature sensors were in contact with the regolith, and the uncertain effects of local topography (both measurements were very close to highland/mare boundaries).

One particularly important measurement would be to determine the heatflow as a function of distance from the Procellarum KREEP Terrain (PKT) on the north-western part of the lunar nearside. Remote sensing measurements have determined that the heat-generating elements $(\mathrm{U}, \mathrm{Th}, \mathrm{K})$ are concentrated at the surface in this area of the Moon, but a question remains over whether this is a surficial effect (owing to excavation of a global underlying layer of incompatible element-rich material by the Imbrium impact), or whether these elements are indeed concentrated in the mantle and/or crust below the PKT. The latter scenario would predict a much higher heatflow in the PKT than elsewhere, and would have major implications for our understanding of the early differentiation and crystallization of the Moon (e.g. [36]). While the Apollo 15 and 17 data do appear to indicate a decrease in heat-flow away from the PKT $\left(21 \pm 3\right.$ and $16 \pm 2 \mathrm{~mW} / \mathrm{m}^{2}$, respectively; [13]), the experimental uncertainties are such that it is far from clear that this trend is statistically significant. In addition, Hagermann and Tanaka [10] have drawn attention to fact that the Apollo results may simply reflect the different thicknesses of (U, Th, K-rich) Imbrium ejecta at the two Apollo sites, and not the underlying mantle heat-flow.

For all these reasons there is a pressing need to extend these measurements to new localities far from the Apollo landing sites (e.g. the polar regions and the farside highlands). Such measurements would greatly aid in constraining 
models of lunar thermal evolution. Finally, we note that in situ measurements of both the temperature and the thermal conductivity of the regolith in permanently shadowed polar regions (which would be inherent in any heatflow measurement) would be valuable in constraining the possibilities for frozen volatiles, which are another of our key scientific objectives (see below). Penetrator deployment of a global heat-flow network would be an attractive means of achieving these objectives.

\subsection{In situ geochemistry}

The only places on the Moon from which samples have been collected in situ are the six Apollo landing sites (Fig. 1) and the three Russian Luna sample return missions from near the Crisium basin on the eastern limb of the nearside. No samples have been returned from the polar regions or the farside, greatly limiting our knowledge of lunar geological processes. Although, statistically, many of the $50+$ lunar meteorites must be derived from these unsampled regions, the provenance, and thus geological context, of any given meteorite is unknown, which limits their value in interpreting lunar geology.

Although sample return missions to a number of currently unsampled regions would be the preferred means of furthering our knowledge of lunar geological diversity, this may not be practical in the short term. An alternative would be to make in situ geochemical measurements, at least of the abundances of the major rock-forming elements (e.g. $\mathrm{Mg}, \mathrm{Al}, \mathrm{Si}, \mathrm{Ca}, \mathrm{Fe}$ and Ti). In principle this could be achieved by X-ray fluorescence spectroscopy, using instruments similar to the X-ray Spectrometer (XRS) designed for Beagle2 [33]. Penetrator-deployed XRS devices therefore have the potential to determine the composition of lunar materials in regions remote from areas sampled to-date. In addition to providing a great deal of information about the geology of the particular sites visited, such measurements would provide additional 'ground truth' for the calibration of remote-sensing instruments on forthcoming lunar orbital missions (e.g. Chandrayaan-1, SELENE, and LRO).

\subsection{Polar volatiles}

As is well known, the Lunar Prospector neutron spectrometer found evidence for enhanced concentrations of hydrogen at the lunar poles, which has been widely interpreted as indicating the presence of water ice in the floors of permanently shadowed polar craters [5]. This potentially very important result is still awaiting confirmation, but if water ice is present it is most likely derived from the impacts of comets with the lunar surface (although solar wind implantation and endogenic sources might also contribute). The confirmation of water ice (and other volatiles) would be important for at least three reasons:

(i) Even though the original cometary volatiles will have been considerably reworked by impact vaporisation, migration to the poles, and subsequent 
condensation, it remains possible that some information concerning the composition of the original sources will remain. Among other things, this may yield astrobiologically important knowledge on the role of comets in 'seeding' the terrestrial planets with volatiles and pre-biotic organic materials (e.g. [2, 27]).

(ii) As pointed out by Lucey [17], lunar polar ice deposits may be of considerable astrobiological interest even if they do not preserve any vestigial information concerning their cometary sources. This is because any such ices will have been continuously subject to irradiation by galactic cosmic rays and, as such, may be expected to undergo 'Urey-Miller-like' organic synthesis reactions. Analogous reactions may be important for producing organic molecules in the icy mantles of interstellar dust grains, and on the surfaces of outer Solar System satellites and comets, but the lunar poles are much more accessible than any of these other locations.

(iii) The presence of water ice at the lunar poles would be a very valuable resource in the context of future human exploration of the Moon (as a potential source of oxygen, rocket fuel and drinking water). Confirmation of its presence would therefore make a significant contribution to the developing Global Exploration Strategy which has renewed human exploration of the Moon as a key element.

We consider that volatile detectors, deployed on penetrators and landed within permanently shadowed craters, would be a powerful and economical means of determining whether or not scientifically and operationally valuable deposits of volatiles exist at the lunar poles.

\section{Mission profile}

The key mission parameters are shown in Table 1. One lunar orbiter spacecraft is required, which carries all the descent modules (4+). Each descent module is deployed from the spacecraft and comprises a de-orbit motor, attitude control system and penetrator, in-essence a micro-spacecraft in its own right. Just prior to impact the descent module motor and attitude control system are ejected from the penetrator. Penetrator releases will occur over a period of $\sim 2$ months. During descent communications from the descent module (including house-

Table 1 Key mission parameters

\begin{tabular}{ll}
\hline Parameters & \\
\hline Mission duration & 1 year \\
Orbiter height & $100 \mathrm{~km}$ \\
Orbit inclination & $\sim 90^{\circ}$ \\
Mean data rate & $30 \mathrm{kbits} /$ day \\
Number of penetrators & 4 (with an option to increase to up to 8) \\
Penetrator location & Widely spaced, including: shaded pole \\
& (e.g. Shackleton), far side, and PKT (e.g. near Apollo 12 site) \\
\hline
\end{tabular}


keeping and descent camera images) would be made via the orbiter using the penetrator's communication system. When line-of-site contact between descent module and orbiter is lost, information would be stored within the penetrator for later transmission. During surface operations the orbiter would relay the penetrator information to the Earth. The nominal mass budget of $846 \mathrm{Kg}$ for a nominal 4 penetrators shown in Table 15 is compatible with a Soyuz-Fregat launch with $\sim 30 \%$ margin.

\subsection{Orbit requirements}

A $100 \mathrm{~km}$ polar lunar orbit would allow deployment of the penetrators in sequence for impact into the lunar surface near the poles, the nearside and

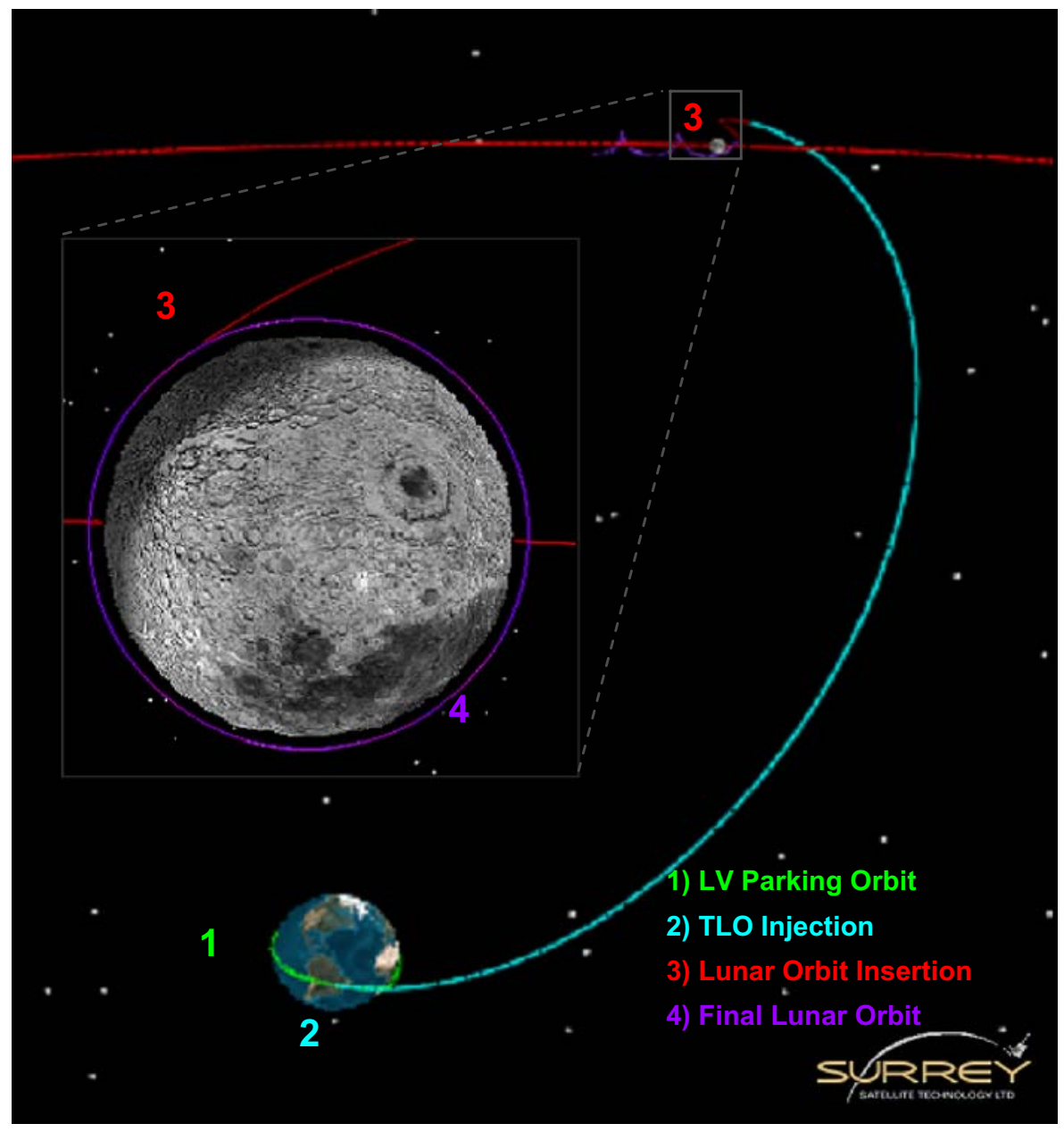

Fig. 3 Earth to Moon transfer 
farside. Surface operation across the lunar globe requires the orbiter to act as a communication relay after penetrator deployment.

Using the MoonLITE mission design as a baseline [6], the spacecraft takes a direct transfer trajectory to the final lunar orbit as illustrated in Fig. 3, which combines a low $\Delta \mathrm{V}$ (reduced propulsion system costs), short EarthSpacecraft distances (simpler communications system) and a short transfer time of approximately 3 days (lower operations cost during transfer).

The descent strategy of the penetrator and associated trajectory (see Fig. 4) is as follows:-

(1) carrier spacecraft first enters a $100 \times 40 \mathrm{~km}$ altitude elliptic orbit; (2) penetrator descent module is released at periapsis; (3) a deceleration burn of approximately $1675 \mathrm{~m} / \mathrm{s}$ cancels orbital velocity; (4) followed by $\sim 3.5 \mathrm{~min}$ free fall to surface; (5) impact; and (6) orbiter moves to final orbit and provides communications relay for penetrator to Earth.

\subsubsection{Penetrator impact error ellipse}

A knowledge of the error ellipse is essential when selecting impact sites. When calculating the size of the error ellipse a number of sources of error must be considered relating to the complex sequence of propulsive manoeuvres required to de-orbit the penetrator. Calculations of the most important factors result in a conservative estimate of $28 \mathrm{~km}$ diameter ellipse [7] which can be compared with crater-targets at the lunar poles. Shackleton (diam $\sim 20 \mathrm{~km}$ ) would require only a modest increase in precision while Mawson (diam

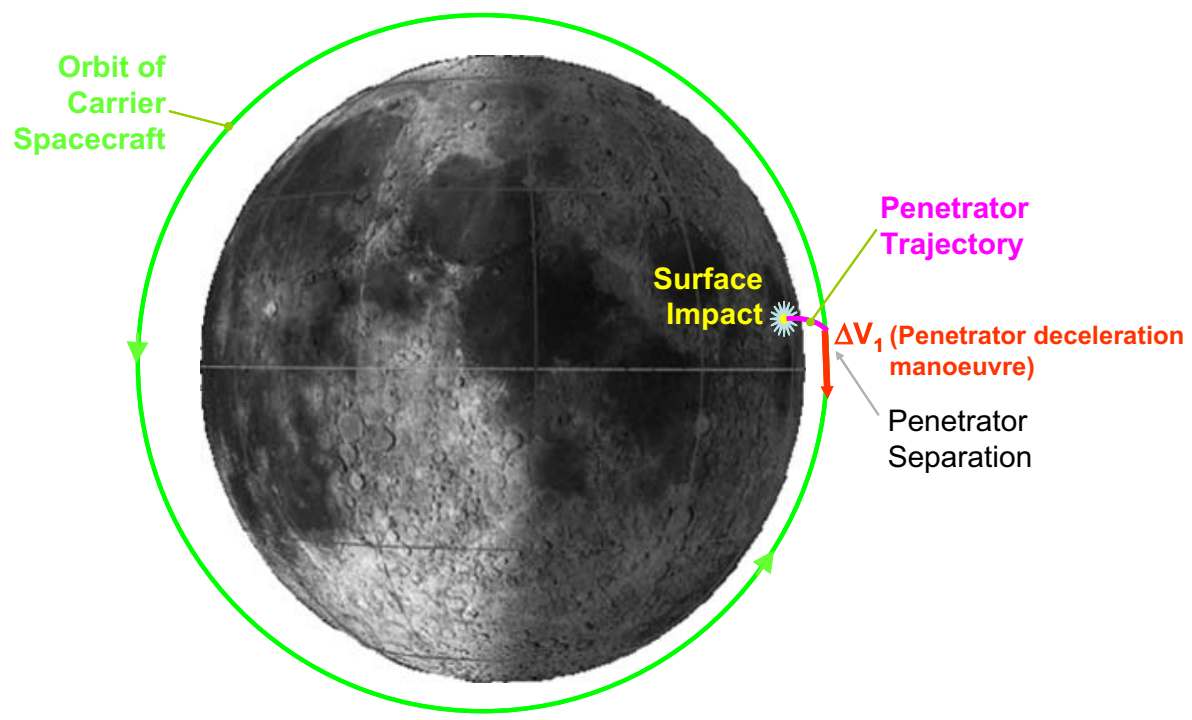

Fig. 4 Penetrator descent trajectory 
Table 2 Penetrator characteristics

\begin{tabular}{ll}
\hline Characteristics & \\
\hline Mass (at impact) & $13 \mathrm{~kg}$ \\
Impact deceleration & $\mathrm{Up} \mathrm{to} 10,000 \mathrm{~g}$ \\
$\begin{array}{l}\text { Impact angle (between impact } \\
\text { velocity vector and tangent to surface) }\end{array}$ & $\sim 90^{\circ}$ (not critical) \\
$\begin{array}{l}\text { Attack angle (between penetrator long } \\
\quad \text { axis and impact velocity vector) }\end{array}$ & $\sim<8^{\circ}$ (critical) \\
Penetration depth into regolith & 2 to $5 \mathrm{~m}$ \\
Ambient penetrator operating temperature & $-20^{\circ} \mathrm{C}$ to $-50^{\circ} \mathrm{C}$. ( $50 \mathrm{~K}$ to $100 \mathrm{~K}$ \\
& in shaded polar craters) \\
Mean penetrator power (subsystems \& payload) & $60 \mathrm{~mW}$ \\
Mission duration & 1.2 years $(1$ year on surface) \\
\hline
\end{tabular}

$\sim 51 \mathrm{~km}$ ) provides an excellent alternative target. For non-crater targets the landing precision is more than adequate.

\section{Payload instruments}

The mission involves the delivery of a minimum of four penetrators into the lunar surface at widely dispersed location. The general characteristics of the penetrators are given in Table 2. Each penetrator comprises a scientific payload and support subsystems (power, communications, data management, structure). During the descent phase a camera (Penetrator Descent Camera) is used to provide impact site location and context information.

The 'strawman' payload elements proposed were derived from a study of science requirements, available technologies and track records associated with earlier penetrator missions. While the payload described suggests a feasible mission, it is recognized that the ultimate selection will depend upon a number of factors including the results of technology develops presently ongoing and available funding within national states (Tables 2 and 3 )

The penetrator scientific payload is described in Table 3 .

Table 3 Penetrator science payload elements

\begin{tabular}{lccl}
\hline $\begin{array}{l}\text { Payload instrument } \\
\text { sub-instrument }\end{array}$ & Mass $(\mathrm{g})$ & $\begin{array}{l}\text { Integrated power } \\
\text { usage over 1 year }(\mathrm{W} \mathrm{h})\end{array}$ & $\begin{array}{l}\text { Telemetry (1 year) } \\
(\text { Mbits })\end{array}$ \\
\hline $\begin{array}{l}\text { Accelerometer and tilt-meter } \\
\text { Geochemistry package }\end{array}$ & 66 & 0.002 & 0.1 \\
Water/volatile experiment & 750 & 12.0 & 0.1 \\
Seismometer & 300 & 501.0 & 2.0 \\
Heat flow & 300 & 1.0 & 6.0 \\
Total penetrator & 1,676 & 516.1 & 0.6 \\
Descent camera & 160 & 0.05 & 8.8 \\
\hline
\end{tabular}




\subsection{Impact accelerometer and tilt-meter}

The main goals of this experiment are:

1. To derive mechanical properties of the lunar regolith vs. depth at each impact site. This is of interest for comparison with existing models of lunar regolith, and to provide context for the geochemistry experiment.

2. To determine the depth below the surface at which each penetrator comes to a rest. This is needed for full interpretation of the thermal data for the heat flow determination.

3. To determine the angle from the local vertical at which each penetrator is tilted. This is needed to determine the orientation of the seismometer axes and to help measure the vertical temperature gradient for the heat flow determination.

4. To provide a full dynamic history of each penetrator impact, for comparison with results from ground testing and simulations.

\subsubsection{Description and key characteristics}

The goals listed above require two types of sensor: accelerometers and tilt sensors (inclinometers).

Accelerometry Two sets of 3-axis accelerometers will need to be located inside the penetrator close to its axis of symmetry. One set shall be mounted close to the penetrator tip, the other close to the penetrator's rear (upper) end. This is to derive the complete motion history of the penetrator (position and orientation) and compensate for the mechanical response of the penetrator structure. The accelerometers would operate during the impact event, sampled rapidly enough to achieve sufficiently fine spatial resolution of the motion. Such measurements are routine in defence applications.

Tilt A two-axis tilt measurement needs to be made to an absolute precision of $0.1^{\circ}$ or better. This is driven by the need to correct the measured temperature gradient for non-vertical orientation of the penetrator and to properly interpret seismic data.

\subsubsection{Performance assessment with respect to science objectives}

Precise determination of the penetrator motion and final depth requires each of the accelerometers to have range, sensitivity, noise, offset performance and frequency characteristics that are compatible with the impact event, as shown in Table 4 for a $300 \mathrm{~m} / \mathrm{s}$ impact speed. 
Table 4 Resource summary for accelerometer and tilt-meter

\begin{tabular}{|c|c|c|}
\hline & Accelerometry & Tilt \\
\hline Mass [g] & 56 for 8 sensors & 10 for 2 axes \\
\hline Volume $\left[\mathrm{cm}^{3}\right]$ & $\sim 1$ per sensor, total $\sim 8$ & 25 \\
\hline Power $[\mathrm{mW}]$ & $<500$ for a short period only (10 s) & $<100$ during measurements \\
\hline $\mathrm{OBDH}$ & $\begin{array}{l}100 \mathrm{kHz} \text { sampling (equivalent to } \\
3 \mathrm{~mm} \text { spatial) with 12-bit resolution for } \\
8 \text { axes, into } 0.1 \mathrm{~s} \text { duration circular buffer, } \\
\text { frozen on impact. Onboard processing } \\
\text { to reduce data volume }\end{array}$ & $\begin{array}{l}1 \mathrm{~Hz} \text { sampling with } 12 \text {-bit } \\
\text { resolution for each of } 2 \text { axes, for } \\
\text { the first minute after impact, } \\
\text { then a few times per lunar day } \\
\text { thereafter. }\end{array}$ \\
\hline Telemetry & 0.1 Mbit total & $1 \mathrm{kbit}$ total \\
\hline
\end{tabular}

\subsubsection{Resources: mass, volume, power, $\mathrm{OBDH}$ and telemetry (Table 3)}

\subsection{Geochemistry package}

\subsubsection{Description and key characteristics}

The aim of the geochemistry element is to greatly improve our understanding of global lunar geochemistry by performing in situ analyses at globally dispersed sites, and to provide contextual information for related payload elements such as the Polar Volatiles detector and accelerometer. The requirement is therefore for one or more techniques that can detect and quantify the major rock-forming elements e.g. $\mathrm{Ca}, \mathrm{Fe}$, Ti.

The baseline instrument is based on the Beagle XRS (X-Ray Spectrometer), and draws on significant heritage from other X-ray spectrometers [31], Pathfinder APXS [32], and Viking Lander XRS). The instrument will view the sample of the lunar regolith brought into the penetrator volume by the micro-drill (see Tables 5 and 6 below). Alternatively, a small X-ray transparent window with shutter could be provided in the rear wall of the penetrator. The selected technique utilises primary excitation provided by two ${ }^{55} \mathrm{Fe}$ (emitting $\mathrm{X}$-rays of 5.90 and $6.49 \mathrm{keV}$ ) and two ${ }^{109} \mathrm{Cd}$ sources (emitting X-rays of 22.16 and $24.94 \mathrm{keV}$ ) for which the fluoresced rays are detected by a Si PiN detector, allowing sensitivity in the $1-27 \mathrm{keV}$ range for detection of elements from $\mathrm{Na}$ to $\mathrm{Nb}$.

\subsubsection{Performance assessment}

Expected accuracies and detection limits: (Tables 5 and 6)

Table 5 XRS accuracy (\%)

\begin{tabular}{lllllllll}
\hline Element & $\mathrm{Si}$ & $\mathrm{K}$ & $\mathrm{Ca}$ & $\mathrm{Ti}$ & $\mathrm{Fe}$ & $\mathrm{Rb}$ & $\mathrm{Sr}$ & $\mathrm{Zr}$ \\
\hline $\mathrm{XRS}$ & - & 11 & 7 & 9.8 & 3.4 & 10 & 15 & 4.7 \\
\hline
\end{tabular}


Table 6 XRS detection limits

\begin{tabular}{|c|c|c|c|c|c|c|c|c|}
\hline ement & $\mathrm{Si}(\mu \mathrm{g} / \mathrm{g})$ & $\mathrm{K}(\mu \mathrm{g} / \mathrm{g})$ & $\mathrm{Ca}(\mu \mathrm{g} / \mathrm{g})$ & $\mathrm{Ti}(\mu \mathrm{g} / \mathrm{g})$ & $\mathrm{Fe}(\mu \mathrm{g} / \mathrm{g})$ & $\mathrm{Rb}(\mu \mathrm{g} / \mathrm{g})$ & $\mathrm{Sr}(\mu \mathrm{g} / \mathrm{g})$ & $\mathrm{Zr}(\mu \mathrm{g} / \mathrm{g})$ \\
\hline & - & 360 & 230 & 120 & 420 & 13 & 14 & 9.0 \\
\hline
\end{tabular}

\subsubsection{Resources: mass, volume, power, OBDH and telemetry (Table 7)}

\subsection{Water/volatile detector}

The measurement of volatile content in the shaded, polar lunar regolith is a key mission objective and in order to provide unequivocal results, whilst ensuring redundancy in this key area, an integrated suite of complementary instruments is proposed.

\subsubsection{Description and key characteristics}

The analysis techniques and sample requirements are listed below: (Table 8)

Note also that the above will also provide in situ measurement of regolith electrical properties important for interpretation of ground-penetrating radar results from orbit.

Sample collection is achieved with a micro-drill mechanism that is activated after impact from the body of the penetrator. During operation the bit extends into the regolith and can deliver material tailings into a cup inside a sample collection container. Following the drilling operation, a pyrotechnic actuator is used to seal the sample container preventing the unwanted escape of evolved gases during sample analysis.

Thermal control is provided by a resistive heater wound around the sample container to enable heating the collected regolith sample. The temperature of the sample during heating (and cooling) is measured by two sensors located inside the sample container. One sensor is attached to the wall of the container and the other is located on a thermally isolated post in the centre of the cup. Gases evolved from the sample during heating are vented through two capillary tubes to either the mass spectrometer or the optical analysis instrument.

Table 7 Geochemistry package resources

\begin{tabular}{|c|c|}
\hline & Geochemistry package \\
\hline Mass $[\mathrm{g}]$ & $\begin{array}{l}\text { [Detector head assembly DHA (60) + back end electronics BEE (100) + Shutter, } \\
\left.\text { window and mechanism }{ }^{\mathrm{a}}(100)\right] \text { Total } 260\end{array}$ \\
\hline Volume $\left[\mathrm{cm}^{3}\right]$ & [DHA, dia. $4.7 \mathrm{~cm} \times$ height $4.7 \mathrm{~cm}+$ BEE $12.0 \times 8.0 \times 1.5 \mathrm{~cm}]$ total 160 \\
\hline Power $[\mathrm{mW}]$ & 4,000 for two periods of $3 \mathrm{~h}$ each \\
\hline $\mathrm{OBDH}$ & No special requirement \\
\hline Telemetry & $50 \mathrm{~kb} /$ spectrum, two spectra \\
\hline
\end{tabular}

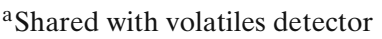


Table 8 Water and volatile detection techniques

\begin{tabular}{lll}
\hline Technique & Method & Sampling requirements \\
\hline Mass spectrometry & Direct & Sample ingress/laser stand-off \\
Spectroscopic & Direct & Sample ingress \\
Mutual impedance spectroscopy & Inferred & Touch sensor \\
Pressure sensor & Inferred & Sample ingress \\
Calorimetric & Inferred & Sample ingress \\
\hline
\end{tabular}

\section{Measurement techniques include:-}

Mutual impedance spectrometer Laboratory studies of lunar simulants have shown that a measurement of mineral dielectric constant is a suitable method of detecting water to levels of $0.1 \%$ (with possible lower detection limits of $0.001 \%)$. The sensors are physically small, simple devices and so can be incorporated into the drilling mechanism, or via a needle probe, to allow rapid in situ measurements to be performed.

Calorimetric analyser The sample heater will be programmed to deliver a stepwise heating profile to elevate the collected regolith materials to above the sublimation point of ice, hold it there for a pre-determined time before turning the heater off and allowing the sample to cool. During the heating-and-hold period, the recorded temperatures and power profile will reflect sample cooling i.e. when ice sublimates more energy is required to maintain the programmed heating ramp so the presence of ice can be detected in the power profile of the heating cycle.

Pressure sensor As the stepped heating profile is conducted, evolved gases will expand into the analysis chamber and re-freeze when the heater power is switched off. The resulting pressure increase/decrease will be measured by a MEMS pressure sensor. The presence of water (and other volatile) ice will be detected in the temperature/pressure profile during sample heating and cooling.

Optical detection system As the stepped heating extraction is conducted, evolved gases will expand into the analysis chamber. Spectroscopic analyses are conducted with a miniature tuneable diode laser scanning across a single water line in the $1.37 \mu \mathrm{m}$ region of the spectrum. The water vapour abundance in the chamber is calculated using Beer's law (e.g. [18])

Mass spectrometer Characterisation and analysis of the evolved gases present in the sample chamber is performed by a miniature ion trap mass spectrometer. The measurement of the volatile composition together with the release temperature of individual volatiles is an effective tool for the identification and characterisation of the minerals and rocks found at the sampling site. A secondary mode of operation using a miniature laser as a stand-off laser ablation device would allow characterisation of regolith mater- 
Fig. 5 Open University prototype, ruggedized ion trap mass spectrometer

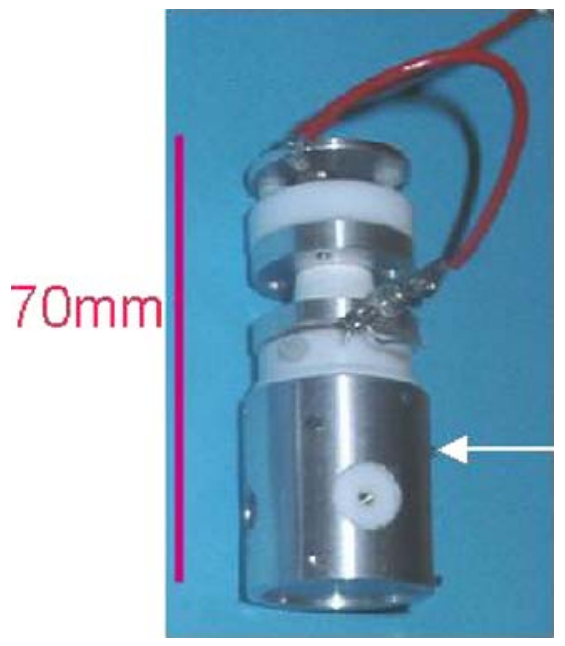

ial through the wall of the penetrator, either in direct line-of-sight, or through a deployable fibre-optic cable. Figure 5 shows a prototype, ruggerdised ion trap mass spectrometer developed by the Open University.

\subsubsection{Performance assessment}

A penetrator-based water detection system utilising a sample drill, pyrotechnic seal, thermal control and spectroscopic detection system was space qualified for the NASA Deep Space-2 mission. Laboratory studies have shown that $0.1 \%$ water content can be detected in lunar analogue material using the impedance spectroscopy technique. The MEMS pressure sensor is a low mass, very rugged, fatigue-free, monocrystaline silicon diaphragm device, which has been qualified and flown on Beagle 2 and Ptolemy (Rosetta Lander) instruments. The ion trap mass spectrometer is an instrument based on that already developed for the Ptolemy instrument. Its small size, low mass and inherent ruggedness lends itself to location on a sub-surface penetrating device. Laboratory testing of a breadboard mass spectrometer system has demonstrated a mass range of 10 to $100 \mathrm{amu}$.

\subsubsection{Resources: mass, volume, power, OBDH and telemetry (Table 9)}

\subsection{The microseismometer}

\subsubsection{Sensor description}

This instrument will be based on a ruggedized version of the microseismometer selected for the ExoMars, for which the sensing elements are MEMSbased micromachined silicon suspensions. These act as a spring/proof-mass system, converting any external vibration to a displacement of the proof mass 
Table 9 Water/volatile package resources

\begin{tabular}{|c|c|}
\hline & Water/volatile detector \\
\hline Mass $[\mathrm{g}]$ & $\begin{array}{l}\text { [Sample collection and thermal control (150), mutual impedance } \\
\text { spectrometer (40), pressure sensor (10), optical detection system (50), } \\
\text { mass spectrometer (200), electronics (300)], total } 750\end{array}$ \\
\hline Volume $\left[\mathrm{cm}^{3}\right]$ & 1,000 \\
\hline Power $[\mathrm{mW}]$ & 3,$000 ;$ duration, $5,000 \mathrm{~s}$ in a number of stages \\
\hline $\mathrm{OBDH}$ & $\begin{array}{l}50 \text { Mbits of data collected in a series of operations, on-board processing and } \\
\text { compression required }\end{array}$ \\
\hline Telemetry & $<2$ Mbits \\
\hline
\end{tabular}

measured using a position transducer. The design of the microseismometer indicating the sensor-head and electronics subsytems is shown schematically in Fig. 6. More details of these subsystems are described in [28-30].

Figure 7 shows the silicon suspension of the microseismometer (fabricated at Imperial College London) which is optimised to produce very good rejection of off-axis modes [29].

\subsubsection{Instrument performance}

The requirements for a seismic investigation of the Moon are based on data recorded during the Apollo programme.

Low-noise, high-sensitivity, well-coupled, isolated from ambient noise All our science objectives require data with adequate signal to noise. The Apollo seismometers were able to acquire such data, and the microseismometer will match the performance of the Apollo instruments (Fig. 8).

Broad bandwidth The majority of the LunarEX seismology objectives require observations of body-waves from moonquakes at regional and teleseismic distances. The microseismometer's bandwidth will be comparable to that of Apollo's.

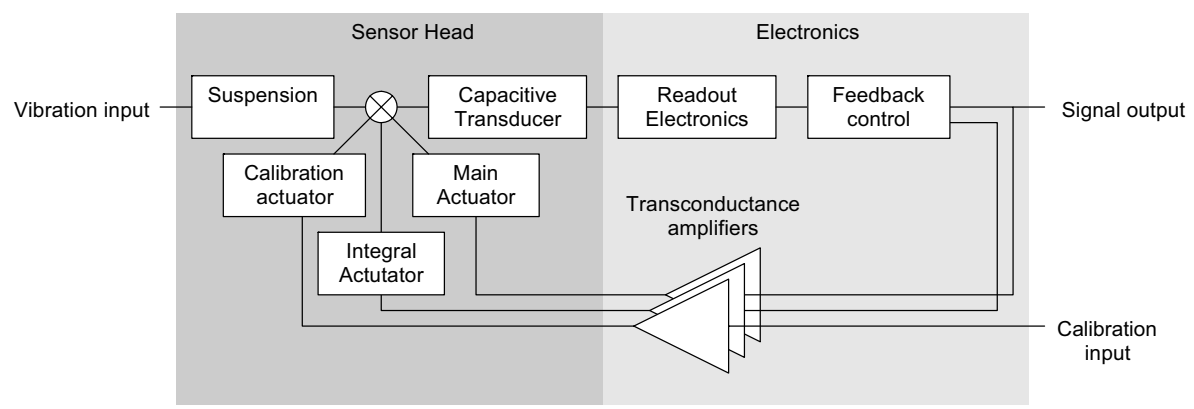

Fig. 6 Schematic of the microseismometer 
Fig. 7 The silicon suspension of the microseismometer. The die is $20 \mathrm{~mm}$ square

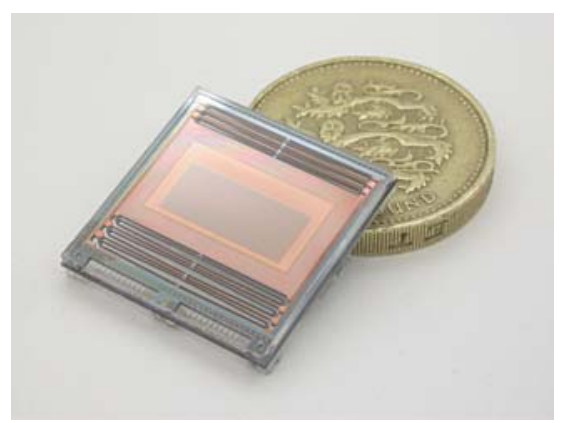

Three matched components The identification of particular phases in body wave data is made more certain, and in difficult cases is only made possible, by using three-component data. A full three-component system is required, with matched horizontal components, in order to identify source direction, and to undertake more than qualitative waveform modelling and analysis. The determination of source depth, source extent, and anisotropy are all dependent upon full three-component data for their complete realisation.

Long operation time To measuring a sufficient number of shallow moonquakes to help elucidate their source requires a long duration. The mission lifetime of 1 year gives a reasonable expectation of sufficient lunar seismic events to meet the LunarEX seismology science objective.

Linearity Determination of scattering and attenuation properties, and waveform modelling for source depth, source extent, anisotropy, and core state, all require a linear instrument with a known amplitude and phase response. Analysis of surface waves has similar requirements (Table 10).

Fig. 8 Comparison of the microseismometer's noise performance to horizontal and vertical axis background lunar seismicity measured during Apollo as calculated by Lognonné and Johnson [38], and the Earth's background seismicity as determined by Peterson [39], (after [40])

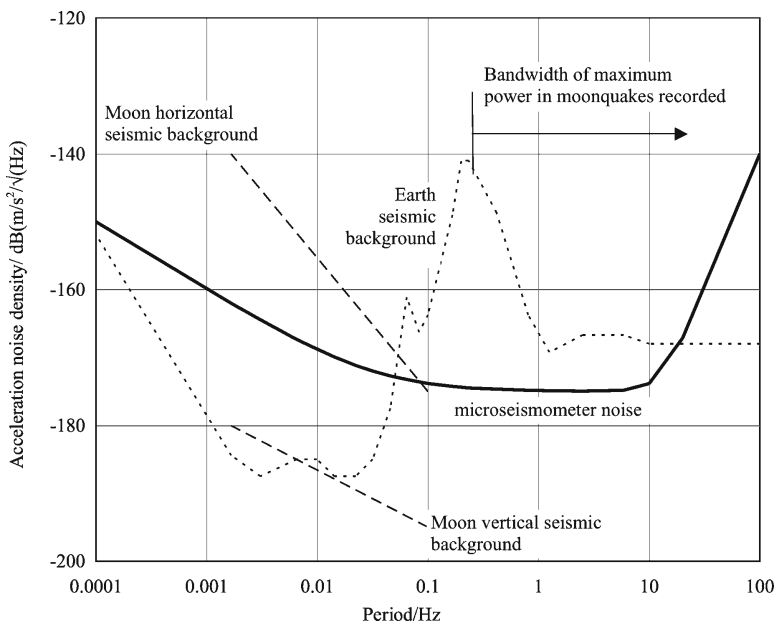


Table 10 Seismometer technical performance requirements

\begin{tabular}{ll}
\hline Parameter & Requirement \\
\hline Noise & $<1 \mathrm{ng} / \sqrt{ }(\mathrm{Hz})$ \\
Bandwidth & 0.03 to $80 \mathrm{~Hz}$ \\
Temp. coefficient & $100 \mathrm{ppm}$ full scale/K \\
Nonlinearity & $<1 \%$ full scale \\
Range & $0.05 \mathrm{~g}$ \\
\hline
\end{tabular}

\subsubsection{Resources: mass, volume, power, OBDH and telemetry (Table 11)}

\subsubsection{Operating modes}

Global network mode 1-axis operation triggering 3-axis operation when a seismic event is detected.

Figure 9 shows typical lunar seismic events from Apollo (notice that the time scale interval is $10 \mathrm{~min}$ ). Note also the relatively larger signal seen in the horizontal axes compared with the vertical (z) axis. This is typical for the Moon but unlike the Earth where the vertical axis normally dominates. It is therefore proposed to use a horizontal axis trigger. The S-P travel times of the phases are typically more than 100 s $[16,24]$ which implies a requirement to initialize the other axes within that time- the microseismometers will have an initialization time of 30 s.

Full operation mode 3 -axis operation

For local seismic events the time-lag between axes will be less and so it is proposed to operate a higher power mode in which all axes are continuously active. To conserve power this mode will operate for 1 month at the beginning of the mission in order to characterize the local seismic environment. For the remaining mission the microseismometer will operate in a power-saving, 'global network mode'.

10 24-bit samples will be taken every second with a bandwidth of $4 \mathrm{~Hz}$, which covers most of the frequency range of moonquake energy. The baseline on-board data compression will be lossless and achieve an approximate threetimes data volume reduction. For short periods a higher rate mode can be considered (200 24-bits samples per second)

Table 11 Seismometer resources

\begin{tabular}{ll}
\hline & Microseismometers \\
\hline Mass $[\mathrm{g}]$ & 3 axes, each 100, total 300 \\
Volume $\left[\mathrm{cm}^{3}\right]$ & 200 \\
Power $[\mathrm{mW}]$ & 53 single axis, 112 full operations \\
OBDH & 10 samples per second/axis each 24 bit. Total data rate 720 bits/s. Data only \\
& transmitted when above a threshold, circular data buffer, 'event detection \\
& algorith'. Data compression. Higher rate sampling tbd for short periods \\
Telemetry & 6 Mbits (corresponding to $\sim 0.5 \%$ time during events) \\
\hline
\end{tabular}



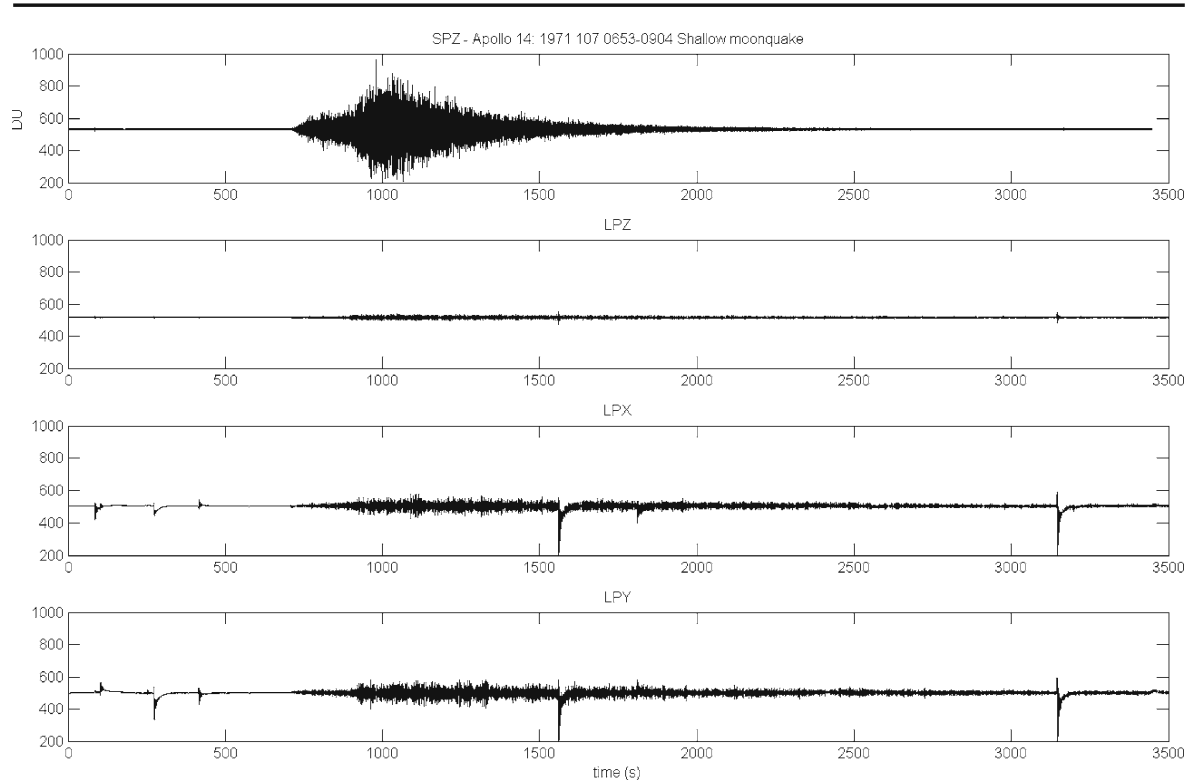

Fig. 9 A shallow moonquake recorded by Apollo 14 with the short period seismometer (SPZ), and the three long-period seismometer axes (LPX, LPY, LPZ)

\subsection{Heat flow experiment}

For measuring planetary heat flow, two parameters are required: the subsurface thermal gradient and the thermal conductivity of the subsurface material (i.e. the regolith). The heat flow experiment would measure the temperature gradient in the lunar regolith by using temperature sensors on the outside of the penetrators. These are accommodated at several locations between nose and tail. The thermal gradient can be determined from temperature measurements once the orientation of the penetrator is known from the tiltmeter. A correction is necessary to deduct the thermal effect of the penetrator from the temperature measurements. The thermal conductivity of the subsurface regolith would be measured in four locations using small plate heaters. Thermal conductivity sensors could be measured using miniaturized needle probes.

\subsubsection{Description and key characteristics}

The heat flow experiment will consist of a number of sensors located on the outside of the penetrator as follows: (1) a suite of 8 relative temperature sensor (thermocouples) on the outside of the penetrator; (2) 4 absolute temperature sensors (Pt-100 or NTC thermistors) on the outside of the penetrator (3) 4 miniature thermal conductivity sensors (e.g. heater plate with thermocouple, or miniaturized needle probe). 


\subsubsection{Performance assessment}

The feasibility of a penetrator-based heat flow experiment has been studied in detail (e.g. [21]). Based on thermal sensors with an accuracy of $0.01 \mathrm{~K}$ Tanaka et al. [20] estimated an accuracy of $10 \%$ for the gradient measurement. Using plate heaters, thermal conductivity can also be measured with an accuracy of $10 \%$. Needle probes increase this accuracy into the $1-2 \%$ range.

\subsubsection{Resources: mass, volume, power, OBDH and telemetry (Table 12)}

\subsection{Penetrator descent camera}

\subsubsection{Description and key characteristics}

The Penetrator Descent Camera (PDC) would not have to withstand impact and so general space qualified camera technology will be suitable. For this the space qualified Beagle-2 PANCAM which are also in development for ExoMars are quite possible at quite low resource of $160 \mathrm{~g}$ and $900 \mathrm{~mW}$, [9], (these values are given as a baseline in Table 3), though we propose a lower mass based on a 'camera on a single chip' 3 Mpixel CMOS detector coupled to a $45^{\circ}$ objective lens (1/3" format) via minimal encapsulating structure. The PDC will image the surface in RGB colour from $40 \mathrm{~km}$ down to $\sim 1 \mathrm{~km}$ altitude to determine landing site location and context; thus supporting the achievement of the science objectives. Below $1 \mathrm{~km}$ the image blur due to motion exceeds the camera resolution.

The camera would interface directly to the penetrator DHU transferring up to 32 Mbit per image (binning operations of $2 \times 2$ and $3 \times 3$ to 1 pixel could be implemented in the DHU to conserve on board mass memory). Therefore, 4 images acquired during the $3 \mathrm{~min} 42 \mathrm{~s}$ decent would require 30 Mbit of uncompressed storage. The storage requirements could be reduced by a factor of 15 by using lossy compression (e.g. wavelet).

Table 12 Heat flow resources

\begin{tabular}{ll}
\hline & Heat flow \\
\hline Mass $[\mathrm{g}]$ & {$[12$ temperature sensors $(120), 4$ thermal property sensors $(80)$, electronics $(100)$.} \\
& Total $=300$ \\
Volume $\left[\mathrm{cm}^{3}\right]$ & 20 \\
Power $[\mathrm{mW}]$ & 25 normal ops, 300 peak \\
OBDH & Temperature measurement: e.g. $1 / \mathrm{h},>18$ bit resolution, depending on chosen \\
& sensor. Thermal property measurement: $50 \mathrm{~Hz}, 12$ bit resolution \\
Telemetry & $<0.5$ Mbit for thermal property \\
& $<0.1$ Mbit for temperature \\
\hline
\end{tabular}


Table 13 PDC specifications

\begin{tabular}{llll}
\hline Size $(\mathrm{l} \times \mathrm{w} \times \mathrm{h})(\mathrm{mm})$ & $10 \times 10 \times 30$ & $\begin{array}{l}\text { Linear resolution } \\
(\mathrm{m} / \text { pixel })\end{array}$ & $\begin{array}{l}120(\text { at } 40 \mathrm{~km}), \\
3(\text { at } 1 \mathrm{~km})\end{array}$ \\
\hline Array size $(\mathrm{w} \times \mathrm{h})$ & $512 \times 512$ & Pixel size & $2.2 \times 2.2(\mu \mathrm{m})$ \\
Output format $($ Bayer matrix $)$ & 10 bit RGB & Angular resolution & $0.3(\mathrm{mrad} / \mathrm{pixel})$ \\
Signal to noise ratio $(\mathrm{dB})$ & 42 & Spatial resolution & $0.3(\mathrm{~m}$ at $1 \mathrm{Km})$ \\
Diagonal field of view $\left({ }^{\circ}\right)$ & 45 & Drive voltage & $2.8(\mathrm{~V})$ \\
Sensitivity $(\mathrm{DN} / \mathrm{s}) /\left(\mathrm{W} / \mathrm{m}^{2} . \operatorname{str} \mu \mathrm{m}\right)$ & 168 & Dynamic range & $50(\mathrm{~dB})$ \\
\hline
\end{tabular}

\subsubsection{Performance assessment}

Expected PDC performance (based on a COTS mobile phone camera module) is shown in the Table 13.

\subsubsection{Resources: mass, volume, power, OBDH and telemetry (Table 14)}

\section{Basic spacecraft key factors}

\subsection{Orbiter}

The mass budget for the orbiter + descent modules is shown in Table 15 . The Orbiter will include for each descent module-accommodation, commanding and telemetry communications (health status), power, and ejection mechanism.

\subsubsection{Attitude and orbit control required}

The AOCS system of the LunarEX spacecraft is required to perform 3-axis pointing for such tasks as orienting the spacecraft during the propulsive mission phases, antenna pointing for communications, directing solar panels towards the sun and launching penetrators towards the desired locations on the lunar surface. After the deployment of the penetrators on the surface, the orbiter would continue to operate and communicate with the surface instruments and with Earth until the end of the mission. During this time $\Delta \mathrm{V}$ orbit maintenance would be performed to ensure adequate visibility with the

Table 14 Descent camera resources

\begin{tabular}{ll}
\hline & Descent camera \\
\hline Mass $[\mathrm{g}]$ & $10(160$ for Beagle-2 camera) \\
Volume $\left[\mathrm{cm}^{3}\right]$ & 3 \\
Power $[\mathrm{mW}]$ & 160 during descent $(\sim 220 \mathrm{~s})$ \\
OBDH & 'Offline' $\times 10$ data compression on 21 images (each 32 Mbits $)$ \\
Telemetry & 2 Mbits to be transmitted over 28 days, some transmitted during descent $($ tbd $)$ \\
\hline
\end{tabular}


Table 15 LunarEX orbiter mass budget for nominal 4 penetrator payload [6]

\begin{tabular}{lc}
\hline Item & Mass $(\mathrm{Kg})$ \\
\hline Structure & 131.0 \\
Communications & 8.4 \\
Power & 28.7 \\
Solar panels & 15.3 \\
AOCS & 44.1 \\
Propulsion & 66.1 \\
OBDHs & 6.5 \\
Environmental & 16.6 \\
Harness & 30.0 \\
Payload (4 descent modules) & 158.4 \\
System margin (platform) & 34.7 \\
Total (dry) & 539.7 \\
Propellant (transfer, LOI, OM) & 296.4 \\
AOCS propellant & 10 \\
Propellant (total) & 306.4 \\
Total (launch) & 846.1 \\
\hline
\end{tabular}

surface instruments and the Earth ground station. The basic AOCS system requirements are summed up as below:

\begin{tabular}{ll}
\hline 3-axis pointing accuracy & 1 degree \\
Array pointing accuracy (all phases) & 5 degree \\
lunar insertion pointing accuracy & 1 degree \\
Mission lifetime & 2 years \\
\hline
\end{tabular}

\subsection{Descent module}

There will be four descent modules, each comprising a penetrator and aft deorbit and attitude control system which is ejected from the penetrator prior to penetrator impact. A descent camera would be mounted on the descent module. The overall mass of each descent module is $39.6 \mathrm{Kg}$.

Upon release from the carrier spacecraft, the penetrator must perform a number of propulsive manoeuvres to safely reach the lunar surface with the correct impact constraints. Typically an impact velocity not exceeding $\sim 300 \mathrm{~m} / \mathrm{s}$ and alignment of body axes no greater than $8^{\circ}$ from the velocity vector (i.e. attack angle). The penetrator is released from the carrier spacecraft with a spin rate of typically $60 \mathrm{rpm}$ to provide initial stability, and a period of typically $5 \mathrm{~min}$ is given to achieve a separation of $10 \mathrm{~m}$ prior to starting the sequence. It is currently assumed that a spin-up and eject mechanism is used; however spin up of the carrier can be investigated as an alternative. The spin rate is limited to that needed for initial stability rather than that required to stabilize during the delta- $\mathrm{V}$ in order to keep the mechanism as simple as possible. Following separation from the orbiter several manoeuvres are performed during the course of the descent. These are (1) Spin-up to 500 rpm; (2) Deceleration burn of approx. 1,675 m/s; (3) Spin-down to $\sim 20 \mathrm{rpm}$; and (4) Spin axis precession. 
Propulsion for the penetrator descent system is based on several technologies. The deceleration burn would use a solid motor due to the short burn duration required to reach the required delta- $\mathrm{V}$ (to minimize gravity losses). However, cold gas, mono-propellant (Hydrazine) and small solid rocket motors technologies were considered for the other phases, for which the baseline selected is for a mono-prop (hydrazine) system for the remaining manoeuvres. This is primarily due to the mass/volume saving over a cold gas system and the simplicity of a single propulsion system for all phases (excluding deceleration burn). The motor developed for Lunar-A and available from Japan is one option.

\subsubsection{Attitude control of penetrator with effect to attack angle/error thereon}

The attitude control system is required to stabilize the penetrator during the firing of the solid motor, and then reorient to the local nadir to an accuracy of approximately 8 degrees and maintain that to impact. The penetrator is very constrained in mass, power and cost, hence these objectives must be met with a minimum of low cost hardware.

The simplest option for stabilizing the penetrator during the $\sim 10$-s burn is to spin about the longitudinal axis. This penetrator is prolate and hence nutationally unstable. Any nutation will grow in the presence of energy dissipation, leading to a flat spin after a given period (minimum energy state). The presence of propellant on board is a prime means of energy dissipation, however the time constant of the nutation growth is expected to be significantly longer than the burn period. Active nutation damping will be required during the spin down period to prevent nutation growth, and may also be applied during spin up and the delta-V.

A fuller study of this issue is provided in [7].

\section{Penetrator}

Each penetrator will be $\sim 0.5 \mathrm{~m}$ long and $\sim 13 \mathrm{~kg}$ mass (similar to Lunar-A) and will be a simple "single-body" type (as opposed to fore-/aft-body types such as Deep Space-2). They will each consist of a supporting structure, a power system, comms system, data handling system, and payload.

Table 16 Penetrator structure options

\begin{tabular}{lclll}
\hline $\begin{array}{l}\text { Penetrator shell material } \\
\text { (for 720 mm length) }\end{array}$ & $\begin{array}{l}\text { Wall } \\
\text { thickness }(\mathrm{mm})\end{array}$ & $\begin{array}{l}\text { Projectile internal } \\
\text { volume }(\mathrm{l})\end{array}$ & $\begin{array}{l}\text { Projectile filling } \\
\text { mass }(\mathrm{kg})\end{array}$ & $\begin{array}{l}\text { Projectile all-up } \\
\text { mass }(\mathrm{kg})\end{array}$ \\
\hline Aluminium alloy & 6.5 & 6.5 & 7.44 & 13.0 \\
Steel & 11.5 & 5.70 & 6.5 & 27.4 \\
Titanium & 2.5 & 7.36 & 8.46 & 10.8 \\
CFRP compression & 7 & 6.4 & 7.33 & 10.5 \\
$\quad$ moulding & & & & \\
\hline
\end{tabular}


Table 17 Penetrator volume requirements

\begin{tabular}{ll}
\hline Payload sub-system & Volume requirements \\
\hline Scientific payload elements & 1.51 \\
Batteries & 1.01 \\
Electronics & 1.51 \\
Total & 5.01 \\
Occupancy factor & $50 \%$ \\
Total required volume & 101 \\
\hline
\end{tabular}

A preliminary study of penetrator structure options has been carried out by QinetiQ [1]. Four alternative materials were considered, steel, aluminium alloy, titanium alloy and carbon composite. A summary of results from this study is shown in Table 16.

These figures should be compared with an estimated payload volume requirement shown in Table 17.

Therefore with Aluminium, Titanium and CFRP penetrator options, masses below the $13 \mathrm{~kg}$ allocation are achievable. Indeed for Titanium and CFRP a further mass saving can be envisaged which would allow the inclusion of additional batteries. This lower mass c.f. Lunar-A arises largely from the significantly lower mass of the seismometer ( $\sim 3 \mathrm{~kg}$ on Lunar-A).

Acknowledgement Elements of this study were funded by the UK's Science and Facilities Research Council.

Open Access This article is distributed under the terms of the Creative Commons Attribution Noncommercial License which permits any noncommercial use, distribution, and reproduction in any medium, provided the original author(s) and source are credited.

\section{References}

1. Church, P.: QinetiQ, LunarEX study report June (2007)

2. Chyba, C.F., Sagan, C.: Endogenous production, exogenous delivery and impact-shock synthesis of organic molecules: an inventory for the origins of life. Nature 355, 125-132 (1992)

3. Crawford, I.A.: The scientific case for renewed human activities on the Moon. Space Policy 20, 91-97 (2004)

4. Crawford, I.A.: The astrobiological case for renewed robotic and human exploration of the Moon. Int. J. Astrobiol. 5, 191-197 (2006)

5. Feldman, W.C., Maurice, S., Binder, A.B., Barraclough, B.L., Elphic, R.C., Lawrence, D.J.: Fluxes of fast and epithermal neutrons from lunar Prospector: evidence for water ice at the lunar poles. Science 281, 1496-1500 (1998)

6. Gao, Y., Phipps, A., Taylor, M., Clemmet, J., Parker, D., Crawford, I.A., Ball, A.J., Wilson, L., Curiel, A., Davies, P., Sweeting, M., Baker, A.: UK lunar science missions: MoonLITE \& moonraker. In: Proc. DGLR Int. Symposium To Moon and Beyond, Bremen, Germany, March (2007)

7. Gao, Y., Phipps, A.: ESA Cosmic Vision Proposal LunarEX, V.2, June (2007)

8. Goins, N.R., Dainty, A.M., Toksoz, M.N.: Lunar seismology-the internal structure of the Moon. J. Geophys. Res. 86, 5061-5074 (1981)

9. Griffiths, A.D., Coates, A.J., Jaumann, R., Michaelis, H., Paar, G., Barnes, D., Josset, J.-L., the PanCam team: Context for the ESA ExoMars rover: the panoramic camera (PanCam) instrument. Int. J. Astrobiol. (2006). doi:10.1017/S1473550406003387 
10. Hagermann, A., Tanaka, S.: Ejecta deposit thickness, heat-flow, and a critical ambiguity on the Moon. Geophys. Res. Lett. 33, L19203 (2006)

11. Jolliff, B.L., Gillis, J.J., Haskin, L.A., Korotev, R.L., Wieczorek, M.A.: Major lunar crustal terranes: surface expressions and crust-mantle origins. J. Geophys. Res. 105(E2), 4197-4216 (2000)

12. Khan, A.: An inquiry into the lunar interior-a non-linear inversion of the Apollo seismic data. J. Geophys. Res. 107, 1-23 (2002)

13. Langseth, M.G., Keihm, S., Peters, K.: The revised lunar heat flow values. Lunar Planet. Sci. Conf. 7, 3143-3171 (1976)

14. Lawrence, D.j., Feldman, W.C., Barraclough, B.L., Binder, A.B., Elphic, R.C., Maurice, S., Thornsen, D.R.: Global elemental maps of the moon: the Lunar Prospector gamma-ray spectrometer. Science 1484 (1998)

15. Lognonné, P.: Planetary seismology. Ann. Rev. Earth. Planet. Sci. 33, 571-604 (2005)

16. Lognonné, P., et al.: A new seismic model of the Moon: implications for structure, thermal evolution and formation of the Moon. Earth. Planet. Sci. Lett. 211, 27-44 (2003)

17. Lucey, P.G.: Potential for prebiotic chemistry at the poles of the Moon. Proc. SPIE 4137, 84-88 (2000)

18. May, R.D., Webster, C.R.: Data-processing and calibration for uneable diode-laser harmonic absorption spectrometer. J. Quant. Spectrosc. Radiat. Transfer 49, 335-347 (1993)

19. Mosher, T.J., Lucay, P.: Polar night: a lunar volatile expedition. In: Proc. 5th IAA International Conference on Low Cost Planetary Missions (2003)

20. Tanaka, S., Yoshida, S., Hayakawa, M., Horai, K., Fujimura, A., Mizutani, H.: Development of the heat flow measurement system by the lunar-A penetrators. Adv. Space Res. 23, 1825-1828 (1999)

21. Tanaka, S., Yoshida, S., Hayakawa, M., Fujimura, A., Mizutani, H.: Thermal model of the lunar-a penetrator and its effect on the accuracy for lunar heat flow experiment. In: Proc. Fourth Int. Conf. on the Exploration and Utilization of the Moon, July 2000 (ESA SP-462)

22. Mizutani, H., Fujimura, A., Tanaka, S., Shiraishi, H., Nakjima, T.: lunar-A mission: outline and current status. J. Earth Syst. Sci. 114(6), 763-768 (2005)

23. Nakamura, Y., et al.: Shallow moonquakes depth, distribution and implications as to the present state of the lunar interior. Proc. lunar Planet. Conf. 10, 2299-2309 (1979)

24. Nakamura, Y.: Seismic velocity structure of the lunar mantle. J. Geophys. Res. 88, 677-686 (1983)

25. Neal, C.R.: The importance of establishing a global lunar seismic network. Paper presented at the 2005 Space Resources Roundtable, Abstract \#2065 (2005)

26. NRC: The Scientific Context for Exploration of the Moon-Final Report, National Research Council, Washington D.C. (2007)

27. Pierazzo, E., Chyba, C.F.: Amino acid survival in large cometary impacts. Meteorit. Planet. Sci. 34, 909-918 (1999)

28. Pike, W.T., Karl, W., Kumar, S., Vijendran, S., Semple, T.: Analysis of sidewall quality in through-wafer deep reactive-ion etching. Microelectron. Eng. 340, 73-74 (2004)

29. Pike, W.T., Standley, I.M.: Determination of the dynamics of micromachined lateral suspensions in the scanning electron microscope. J. Micromechanics Microengineering 15, S82-S88 (2005)

30. Pike, W.T., Standley, I.M., Syms, R.R.A.: Micromachined accelerometer U.S. Patent 7, 36-374 (2006)

31. Potts, P.J., Webb, P.C. Williams-Thorpe, O., Kilworth, R.: Analysis of silicate rocks using field-portable X-ray fluorescence instrumentation incorporating a mercury (II) iodide detector. Analyst 120(5), 1273-1278 (1995)

32. Rieder, R., Economou, T., Wänke, H., Turkevich, A., Crisp, J., Brückner, J., Dreibus, G., McSween, H.Y.: The chemical composition of Martian soil and rocks returned by the mobile alpha proton x-ray spectrometer: preliminary results from the x-ray mode. Science $\mathbf{2 7 8}$, 1771-1774 (1997)

33. Sims, M.R., et al.: Adv. Space Res. 23, 1925-1928 (1999)

34. Spudis, P.D.: The Once and Future Moon. Smith. Inst. Press (1996)

35. Vaniman, D., Reedy, R., Heiken, G., Olhoeft, G., Mendell, W.: The lunar environment. In: The lunar Sourcebook, CUP, pp. 27-60 (1991) 
36. Wieczorek, M.A., Phillips, R.J.: The "Procellarum KREEP Terrane": Implications for mare volcanism and lunar evolution. J. Geophys. Res. 105(E8), 20,417-20,430 (2000)

37. Wieczorek, M.A., Jolliff, B.L., Khan, A., Pritchard, M.E., Weiss, B.P., Williams, J.D., Hood, L.L., Righter, K., Neal, C.R., Shearer, C.K., McCallum, I.S., Tompkins, S., Hawke, B.R., Peterson, C., Gillis, J.J., Bussey, B.: New views of the moon. Rev. Min. Geochem. 60, 221-364 (2006)

38. Lognonné, P., Johnson, C.L.: Planetary Seismology in Treatise on Geophysics. In: Spohn T. (ed.) vol. 10, pp. 69-123 (2007)

39. Peterson, J.: Observations and modeling of seismic background noise. U. S. Geol. Surv., Openfile Rep. 93-322 (1993)

40. Wielandt, E., Streickeisen, G.: The leaf spring seismometer: design and performance. Bull. Seism. Soc. Am. 49, 294-303 (1982) 